\title{
PENERAPAN MODEL TEAM-ASSISTED INDIVIDUALIZATION (TAI) DENGAN GAYA PEMBELAJARAN VISUAL, AUDITORI, DAN KINESTETIK (VAK) UNTUK MENINGKATKAN KEMAMPUAN MENULIS KARANGAN PERSUASI PADA PESERTA DIDIK SMA NEGERI 1 RANCAEKEK
}

\author{
Julianto, M.Pd \\ STKIP Subang \\ zoelliantoe@ymail.com
}

\begin{abstract}
Writing is activity for exercise think ability become more than creative, productive, and expressive. Writing need diligence for develop essay design with the best. Writing skil have to training continual because writing not simple. This study have for question respond: (1) how planning writing skil persuasive essay use application team-assisted individualization with the style learning visual, auditori, and kinesthetic on the student class X SMAN 1 Rancaekek, (2) how implementation writing skil persuasive essay use application team-assisted individualization with the style learning visual, auditori, and kinesthetic on the student class X SMAN 1 Rancaekek, (3) how result writing skil persuasive essay use application team-assisted individualization with the style learning visual, auditori, and kinesthetic on the student class $X$ SMAN 1 Rancaekek. This study tested the three cycle. Based on the study results, cycle one value persuasive essay is 55,4. The cycle two value persuasive essay is 68,5 , and cycle three experience raise value become 80,2 . So, the learning persuasive essay use application teamassisted individualization with the style learning visual, auditori, and kinesthetic on the student class X SMAN 1 Rancaekek can support the raise study achievement for student.
\end{abstract}

Keywords: learn writing persuasive, model team-assisted individualization with the style learning visual, auditori, and kinesthetic, classroom action research methods, and the results of study.

\begin{abstract}
ABSTRAK
Menulis merupakan kegiatan untuk melatih kemampuan berpikir menjadi lebih kreatif, produktif, dan ekspresif. Menulis membutuhkan ketekunan untuk mengembangkan kerangka karangan dengan baik. Keterampilan menulis harus latihan secara terus-menerus karena menulis tidaklah mudah. Penelitian ini bertujuan untuk menjawab pertanyaan: (1) bagaimana perencanaan pembelajaran keterampilan menulis karangan persuasi menggunakan penerapan model team-assisted individualization dengan gaya belajar visual, auditori, dan kinestetik pada siswa kelas X SMA Negeri 1 Rancaekek, (2) bagaimana pelaksanaan pembelajaran keterampilan menulis karangan persuasi menggunakan penerapan model team-assisted
\end{abstract}


individualization dengan gaya belajar visual, auditori, dan kinestetik pada siswa kelas X SMA Negeri 1 Rancaekek, (3) bagaimana hasil pembelajaran keterampilan menulis karangan persuasi menggunakan penerapan model team-assisted individualization dengan gaya belajar visual, auditori, dan kinestetik pada siswa kelas X SMA Negeri 1 Rancaekek. Penelitian ini diujicobakan tiga siklus. Berdasarkan hasil penelitian, siklus satu nilai karangan persuasi adalah 55,4. Siklus kedua sebesar 68,5 , dan siklus ketiga nilai mengalami peningkatan menjadi 80,2 . Jadi, pembelajaran menulis karangan persuasi menggunakan penerapan team-assisted individualization dengan gaya belajar visual, auditori, dan kinestetik pada siswa kelas X-9 SMA Negeri 1 Rancaekek dapat membantu meningkatkan prestasi belajar untuk siswa.

Kata kunci : pembelajaran menulis persuasi, model team-assisted individualization dengan gaya pembelajaran visual, auditori, dan kinestetik, metode penelitian tindakan kelas, dan hasil penelitian.

\section{A. PENDAHULUAN}

Berdasarkan sebaran angket di kelas X-3 SMA Negeri 1 Rancaekek menunjukkan permasalahan pembelajaran menulis karangan persuasi. Pada umumnya sebagian siswa cukup memahami tentang karangan persuasi. Akan tetapi ada beberapa siswa belum produktif dan memahami karangan persuasi dengan baik. Dari data angket tersebut, dapat disimpulkan di kelas $\mathrm{X}-3$ SMA Negeri 1 Rancaekek yang produktif menulis karangan persuasi hanya $68,4 \%$, sedangkan yang belum produktif $31,6 \%$.

Selama ini banyak jurnal penelitian permasalahan

terkait pembelajaran menulis. Cahyani (2009: 163-164) dengan judul "Menulis Antara Harapan dan Kenyataan", mengungkapkan pembelajaran menulis selama ini yaitu sebagai berikut.

Selama ini masih sering terjadi pembelajaran menulis dilakukan dengan memberi tugas. Selain itu, dalam pemerolehan keterampilan menulis sering kali mengikuti naluri saja karena tidak mendapatkan bimbingan. Pembelajaran menulis memang sangat kompleks. Untuk itu diperlukan proses pembelajaran menulis sejak pertama kali peserta didik mengenal bangku sekolah baik PAUD maupun SD. 
Kemampuan menulis sejak SD akan memberikan landasan yang kuat untuk kegiatan menulis selanjutnya pada jenjang yang lebih tinggi yaitu SMP, SMA, dan PT.

Penelitian tersebut terbukti bahwa menulis bukan hanya mengikuti naluri saja. Menulis perlu praktik dan bimbingan intensif dari guru. Menulis harus diajarkan sejak usia sedini mungkin, agar mempunyai landasan yang kuat untuk menulis lebih baik. Sumber penelitian lain yang mengungkapkan permasalahan terkait dengan pembelajaran menulis adalah penelitian Kurniawan (2009: 171-172) dengan judul "Meningkatkan Keterampilan Menulis Mahasiswa dengan Pendekatan Kolaboratif".

Pertama, tradisi membaca perlu digiatkan terutama dalam kehidupan perkotaan yang semakin marak ditandai pengaruh media massa pandang dengar. Membaca perlu dilatih untuk memantapkan kemampuan pemikiran konseptual yang tercermin dari kegiatan merumuskan kata atau ungkapan yang mewakili gejala dalam kehidupan nyata. Kedua adalah tradisi menulis. Tradisi menulis perlu dimantapkan untuk melatih memadukan olah otak dengan gerak tangan, kegiatan psikomotororik yang langka dikalangan cendekiawan, guru/dosen, mahasiswa, dan kalangan profesional yang cenderung mengandalkan komputer dan media pandang dengar, khususnya televisi. Menulis melatih orang untuk cermat dalam merancang jalan pemikiran yang terukur berupa karya tulis.

Penelitian tersebut terbukti bahwa kegiatan baca-tulis merupakan suatu tradisi yang tidak dapat dipisahkan. Arus globalisasi menuntut setiap orang untuk memiliki tradisi membaca dan menulis yang baik untuk menunjang kehidupan kegiatan belajar mengajar, serta dalam menyemarakan dan menggairahkan kebudayaan nasional. Permasalahan yang berkaitan dengan menulis di 
tengah arus global adalah pemanfaatan metode, model, dan media yang kurang interaktif dan efektif, sehingga kemampuan psikomotorik para peserta didik menurun.

Sumber penelitian lain yang mengungkapkan permasalahan terkait dengan pembelajaran menulis adalah penelitian Widodo (2009:93-94), dengan judul "Teori Belajar Gestalt dalam Pembelajaran Menulis".

Sudah saatnya pembelajaran diarahkan kepada cara belajar siswa aktif. Guru atau dosen mampu merencanakan dan menciptakan suasana belajar yang interaktif dengan melibatkan siswa saling bekerja sama. Belajar lebih diarahkan kepada proses sosial yaitu membangun pengetahuan secara bersama-sama. Penelitian ini bertujuan mendeskripsikan hasil pembelajaran menulis yang berlandaskan teori belajar Gestalf. Salah satu strategi yang berlandasakan teori tersebut adalah model pembelajaran investigasi kelompok.
Penelitian tersebut terbukti bahwa teori Gestalt dalam pembelajaran menulis memberikan suatu peningkatan proses pembelajaran. Selama ini metode dan model pembelajaran masih bersifat konvensional. Teori Gestalt menggambarkan suatu model kooperatif yang lebih mementingakan kerjasama tim atau kelompok, sehingga pembelajaran secara individual menjadi tidak efektif. Pembelajaran menggunakan investigasi kelompok memberikan alternatif bagi pembelajaran menulis, agar lebih interaktif dan kreatif.

Selanjutnya

Sutarman (2009:178) dengan judul "Pengajaran Kooperatif Tipe Student Team Achievment Division (STAD) bagi Peningkatan Kemampuan Menulis", mengungkapkan sebagai berikut. Salah satu model pembelajaran yang mengaktifkan proses pembelajaran menulis adalah model mengajar kooperatif Tipe Student Team Achievment Division (STAD). Model ini merupakan cabang dari model pembelajaran 
kooperatif (cooperatif learning), yang berusaha memberdayakan interaksi antar siswa dalam dinamika kelompok. Apabila diterapkan secara khusus untuk pembelajaran keterampilan menulis, siswa akan memiliki keleluasaan, baik dalam mencurahkan gagasanya maupun memberi masukan atau kritikan pada karangan teman sejawatnya dalam kelompok.

Penelitian tersebut terbukti bahwa model Student Team Achievment Division (STAD) mempunyai kesama dengan model yang peneliti kembangkan yaitu penerapan model team-assisted individualitazion (TAI). Model STAD dan TAI merupakan cabang dari model kooperatif (cooperative learning). Model STAD dan TAI digunakan untuk meningkatkan kemampuan menulis siswa dengan mementingkan interaksi sosial dan kerjasama yang lebih interaktif.

\section{Alternatif}

pemecahan masalah untuk meningkatkan pembelajaran menulis persuasi di SMA Negeri 1 Rancaekek, harus mengembangkan sebuah penerapan model pembelajaran team-assisted individualization (TAI) dengan gaya belajar visual, auditori, dan kinestetik (VAK).

]Penerapan model team assisted individualization (TAI) merupakan model dengan mengombinasikan kemampuan kelompok dengan tidak mengesampingkan kemampuan individu siswa. Sedangkan gaya belajar visual, auditori, dan kinestetik (VAK) merupakan gaya belajar multi sensori dalam menerima informasi, yang terdiri dari pengelihatan, pendengaran, dan gerakan.

Untuk meningkatkan kemampuan menulis karangan persuasi, membutuhkan pengelompokan siswa heterogen menggunakan penerapan model team-assisted individualization. Kemudian untuk menangkap informasi lebih baik dibutuhkan gaya belajar visual, auditori, dan kinestetik (VAK). Model dan gaya belajar ini perlu dikolaborasikan, agar kemampuan siswa dalam menulis karangan persuasi meningkat. Penerapan model 
team-assisted individualization

(TAI) dengan gaya belajar visual, auditori, dan kinestetik (VAK), ditunjang dengan pemanfaatan media yang kreatif dan inovatif.

Kelebihan dari penelitian penerapan model team-assisted individualization (TAI) dengan gaya belajar visual, auditori, dan kinestetik (VAK) dalam menulis karangan persuasi, adanya pemanfaatan media seperti fotografi, slide powerpoint, dan movie maker.

\section{B. LANDASAN TEORI}

Slavin (2010:187) teamassisted idividualization (TAI) adalah sebuah program untuk mengadaptasi pengajaran terhadap perbedaan individual berkaitan dengan kemampuan siswa maupun pencapaian prestasi siswa. Pengembangan model team-assisted individualization (TAI) mendukung praktik-praktik semacam pengelompokan siswa, pengelompokan kemampuan di dalam kelas, pengajaran yang terprogram, pengajaran dengan komputer, serta menguasai pelajaran sebagai cara untuk memastikan bahwa kebutuhan dan kesiapan para siswa telah benarbenar ikut diperhitungkan dalam pengajaran.

\section{Team-assisted}

individualization (TAI) diprakasai untuk menyelesaikan masalahmasalah individual dengan pengajaran kelompok, sehingga metode pengajaran individual menjadi tidak efektif. Dengan demikian, model ini membuat para siswa berkelompok, mengembangkan tanggung jawab, mengelola dan memeriksa secara rutin, saling membantu, saling memberi dorongan untuk maju, serta membebaskan guru memberikan pengajaran langsung kepada sekolompok kecil siswa (Slavin, 2010:189-190).

Meskipun kebanyakan orang memiliki akses ketiga modalitas visual, auditorial, dan kinestetik hampir semua orang cenderung pada salah satu modalitas belajar (Bandler dan Grinder, 1981) yang berpesan sebagai saringan untuk pembelajaran, pemerosesan, dan komunikasi. Orang tidak hanya 
cenderung pada satu modalitas, mereka juga memanfaatkan kombinasi modalitas tertentu yang memberi mereka bakat dan kekurangan alami tertentu, Markova, (1992 dalam Deporter, Reardon, dan Nourie-Singer, 2002:85).

Berdasarkan pendapat para ahli di atas, peneliti dapat mengungkapkan bahwa gaya belajar visual, auditori, dan kinestetik (VAK) adalah gaya belajar multi-sensori yang melibatkan tiga unsur gaya belajar yaitu pengelihatan, pendengaran, dan gerakan. Gaya belajar multisensori ini mengharapkan siswa tidak cenderung menggunakan pada satu modalitas saja, tetapi mengkombinasikan semua gaya belajar untuk memberi siswa bakat dan menutupi segala kekurangan yang dimiliki siswa. Dengan memanfaatkan ketiga gaya belajar tersebut, diharpakan dapat mengembangkan pengetahuan, kemampuan, dan motivasi siswa dalam belajar.

Alwasilah dan Suzana (2007:43) mengungkapkan menulis adalah sebuah kemampuan, kemahiran, dan kepiawaian seseorang dalam menyampaikan gagasanya ke dalam sebuah wacana, agar dapat diterima oleh pembaca yang heterogen baik secara intelektual maupun sosial. Selanjutnya Tarigan

mengungkapkan

menulis merupakan suatu keterampilan berbahasa yang dipergunakan untuk berkomunikasi secara tidak langsung. Menulis merupakan suatu kegiatan yang produktif dan ekspresif.

$$
\text { Keraf (2010: }
$$
mengungkapkan bahwa persuasi adalah suatu seni verbal yang bertujuan untuk meyakinkan seseorang, agar melakukan sesuatu yang dikehendaki pembicara pada waktu ini atau pada waktu yang akan datang. Tujuan karangan persuasi, agar pembaca atau pendengar melakukan sesuatu, maka persuasi dapat di masukan pula dalam cara-cara untuk mengambil keputusan. Mereka yang menerima persuasi harus 
mendapat keyakinan, bahwa keputusan diambilnya merupakan keputusan yang benar dan bijaksana dan dilakukan tanpa paksaan.

\section{Finoza}

(2007:229)

mengungkapkan, bahwa karangan persuasi adalah karangan yang bertujuan membuat percaya, yakin, membujuk akan hal-hal yang dikomunikasikan yang mungkin berupa fakta, suatu pendirian umum, suatu gagasan pendapat atau perasaan seseorang. Dalam karangan persuasi, fakta-fakta yang relevan dan jelas harus diuraikan sedemikian rupa, sehingga kesimpulannya dapat diterima secara meyakinkan. Di samping itu, dalam menulis karangan persuasi harus pula diperhatikan penggunaan diksi yang berpengaruh kuat terhadap emosi atau perasaan pembaca.

Finoza

(2007:229-233)

mengungkapkan, bahwa karangan persuasi digolongkan menjadi empat macam yaitu (1) persuasi politik, (2) persuasi pendidikan, (3) persuasi advertensi, dan persuasi propaganda.

\section{METODE PENELITIAN}

Metode yang digunakan adalah "classroom action research" atau penelitian tindakan kelas (PTK). Penelitian tindakan kelas (PTK) dilaksanakan secara sistematis, terencana, dan dengan sikap mawas diri. Maksud dari sistematis, terencana, dan mawas diri adalah setiap langkah penelitian tindakan kelas harus terprogram dan penuh kesadaran, sehingga dapat diketahui aspekaspek mana yang perlu ditingkatkan dan diperbaiki demi ketercapaian kompetensi yang ditargetkan (Muslich Masnur, 2009: 10).
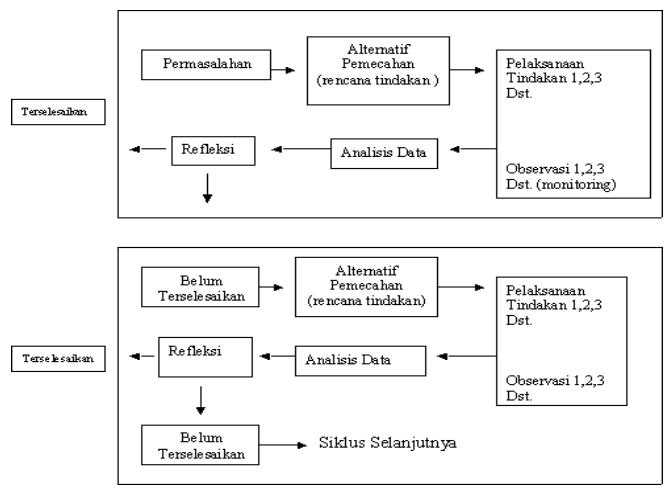

Gambar 1 Alur Kegiatan PTK

]

Dalam penelitian ini menggunakan beberapa teknik pengumpulan data yaitu observasi dengan melakukan penyebaran angket, wawancara, tes tertulis, 
lembar observasi guru dan siswa, jurnal siswa, catatan lapangan, dan rencana pelaksanaan pembelajaran tentang menulis karangan persuasi. Data-data penelitian ini dikumpulkan selama proses penelitian berlangsung, kemudian diadakan reduksi data untuk mengkategorikan data. Analisis data kualitatif maupun kuantitatif terlebih dahulu dianalisis, kemudian dideskriptifkan dengan menapilkan hasil data yang digambarkan dengan tabel untuk selanjutnya dipresentasikan. Setelah data dianalisis dan dideskripsikan, maka selanjutnya yaitu direflesikan untuk menarik kesimpulan.

Setelah data terkumpul dari hasil penelitian, selanjutnya dilakukan pengolahan data. Adapun langkah-langkah pengolahannya sebagai berikut.

1) Peneliti menginventarisasi data yaitu mengumpulkan angket, lembar observasi catatan lapangan dan hasil karangan persuasi siswa.

2) Peneliti menganalisis data yaitu memeriksa dan menafsirkan hasil observasi catatan lapangan, serta menganalisis hasil karangan persuasi siswa setiap siklusnya dengan menggunkan indikator keberhasilan produk tindakan. Namun, sebelum menginterpretasikan data yang telah dikumpulkan, ada beberapa hal yang harus lakukan yaitu:

a) Mendeskripsikan pendahuluan,

b) Mendeskripsikan perencanaan pelaksanaan tindakan setiap siklus,

c) Mendeskripsikan pelaksanaan tindakan tiap siklus, dan

d) Menganalisis data berupa hasil belajar siswa dari setiap tindakan untuk mengethui keberhasilan penelitian yang telah dilakukan.

\section{PEMBAHASAN}

Sebagian besar siswa mengalami peningkatan dengan menggunakan penerapan teamassisted individualization dengan gaya belajar visual, auditori, dan kinestetik dalam menulis karangan 
persuasi mendapatkan hasil nilai yang signifikan.

Dengan penerapan teamassisted individualization dengan gaya belajar visual, auditori, dan kinestetik terbukti meningkatkan kualitas menulis karangan persuasi siswa. Penerapan team-assisted individualization dengan gaya belajar multi sensorik ditunjang dengan media yang mengalami modifikasi di setiap siklusnya. Penerapan model team-assisted individualization dengan gaya belajar visual, auditori, dan kinetetik terbukti membantu kesulitan atau kendala siswa dalam kegiatan belajar megajar karangan persuasi.

Penilain hasil kemampuan menulis karangan persuasi siswa setiap siklus mengalami peningkatan. Berikut adalah skor dan rata-rata nilai hasil karangan persuasi siswa di kelas X-9 dari siklus satu sampai tiga.

Siklus satu terdapat $6,1 \%$ yang termasuk kategori sangat kurang (SK), kemudian siklus berikutnya tidak terdapat siswa yang termasuk kategori ini.
Kategori kurang (K) siklus satu sebesar 45,4 \%, lalu jumlahnya menurun pada siklus kedua, yaitu sebesar 15,1\%, sedangkan pada siklus ketiga tidak terdapat siswa yang masuk kategori ini. Kategri cukup (C) siklus satu sebesar 42,4 , $\%$, sedangkan siklus kedua mengalami kenaikan 57,6 , \%, dan siklus ketiga mengalami penurunan menjadi 45,4 \%. Siklus satu, kategori baik (B) sebesar $6,1 \%$, sedangkan siklus kedua mengalami kenaikan yaitu menjadi $27,3 \%$ dan siklus ketiga mengalami kenaikan lagi menjadi 33,3 \%. Kategori sangat baik (SB) siklus satu dan kedua tidak ada siswa yang masuk kategori ini, sedangkan siklus ketiga mengalami kenaikan yang signifikan 21,2 \%. Untuk nilai ratarata siswa dalam menulis karangan persuasi siklus satu 55,4 . Siklus kedua mengalami pengingkatan menjadi 68,5, sedangkan untuk siklus ketiga mengalami kenaikan yang signifikan menjadi 80,2.

Berdasarkan uraian di atas, membuktkan pembelajaran 
menulis karangan persuasi

menggunakan penerapan model team-assisted individualization dengan gaya belajar visual, auditori, dan kinestetik terhadap kelas X-9 di SMA Negeri 1 Rancaekek tahun ajaran 2010/2011 efektif, kreatif dan produktif dalam meningkatkan keterampilan menulis karangan persuasi.

\section{E. KESIMPULAN}

Penerapan team-assisted individualization (TAI) dengan gaya belajar visual, auditori, dan kinestetik (VAK) untuk meningkatkan keterampilan menulis karangan persuasi ini, ditinjau dari aspek perencanaan, pelaksanaan, dan hasil pembelajaran sebagai berikut.

1. Aspek Perencanaan

\begin{tabular}{lrr}
$\begin{array}{l}\text { Peranan } \\
\text { perencanaan }\end{array}$ & \multicolumn{1}{c}{ ini, } & $\begin{array}{r}\text { pada } \\
\text { sebagai }\end{array}$ \\
perancang & \multicolumn{2}{c}{ perencanaan } \\
pembuatan & skenario & (RPP) \\
yang akan diberikan & kepada \\
siswa. & Peranan observer \\
sebagai & pemantau & proses \\
jalanya & kegiatan & belajar
\end{tabular}

mengajar (KBM) yang mengamati prilaku serta aktivitas guru dan siswa ketika kegiatan belajar mengajar (KBM) sedang berlangsung. Hasil observasi dari para observer dapat mempengaruhi dan memperbaiki skenario (RPP) yang dibuat oleh peneliti untuk melakukan penelitian tindakan.

b. Perencanaan penelitian tindakan siklus satu menindaklanjuti temuan data yang diperoleh pada studi pendahuluan. Hasil studi pendahuluan tersebut menunjukan bahwa semua siswa di kelas X-9 SMA Negeri 1 Rancaekek belum mampu menulis karangan persusi dengan baik dan benar.

c. Perencanaan kegiatan belajar mengajar (KBM) pada setiap siklus, berdasarkan hasil refleksi pada siklus sebelumnya.

2. Aspek Pelaksanaan

a. Pemberian tindakan pembelajaran pada setiap siklusnya dengan menggunakan penerapan model team-assisted 
individualization (TAI) dengan

gaya belajar visual, auditori, dan kinestetik (VAK).

b. Dalam proses perbaikan karangan persuasi dilakukan siswa dan guru. Siklus satu, kedua, dan ketiga guru mengevaluasi dan memperbaiki hasil karangan persuasi berdasarkan catatan atau masukan yang diberikan secara langsung.

3. Aspek Hasil

a. Hasil pada kegiatan belajar mengajar (KBM) 'tidak terlepas dari instrumen penelitian tindakan yang telah dibuat. Pertama hasil diperoleh dari proses kegiatan observasi selama kegiatan belajar mengajar (KBM) berlangsung. Kedua hasil diperoleh dari proses nilai kemampuan menulis karangan persuasi siswa. Ketiga diperoleh dari proses hasil jurnal harian siswa. Instrumen tindakan merupakan cara untuk mengetahui perkembangan dan keberhasilan menulis karangan persuasi siswa. b. Karangan persuasi siswa menunjukan peningkatan setiap siklusnya. Hal ini dibuktikan dengan peningkatan rata-rata nilai siswa. Siklus satu nilai ratarata menulis karangan persuasi siswa adalah 55,4. Siklus kedua mengalami peningkatan 68,5. Kemudian siklus ketiga siswa mengalami peningkatan lagi menjadi 80,2 . Melihat hasil yang ditemukan pada penelitian ini, pembelajaran menulis karngan persuasi menggunakan penerapan team-assisted individualization (TAl) dengan gaya belajar visual, auditori, dan kinestetik (VAK) pada siswa kelas X-9 SMA Negeri 1 Rancaekek dapat membantu meningkatkan prestasi belajar mengajar.

Data di atas, menunjukkan bahwa penerapan team-assisted individualization (TAI) dengan gaya belajar visual, auditori, dan kinestetik (VAK) efektif, kreatif, dan produktif meningkatkan kemampuan menulis karangan persuasi siswa. 


\section{DAFTAR PUSTAKA}

Akhadiah, Arsjad, dan Ridwan. (2003). Pembinaan Kemampuan Menulis Bahasa Indonesia. Jakarta: Erlangga.

Alwasilah, Suzanna. (2007). Pokoknya Menulis. Bandung : PT Kiblat Buku Utama.

Arikunto, Suharsono, dan Supardi. (2009). Penelitian Tindakan Kelas. Jakarta: Bumi Aksara.

DePorter, Reardon, dan NouriSinger. (2002). Quantum Teaching. Diterjemahkan oleh Ary Nilandari Bandung: Mizan Media Utama (MMU).

Djuharie, Suherli. (2005). Panduan Membuat Karya Tulis. Bandung: CV. Yrama Widya.

Finoza Lamuddin. (2007). Komposisi Bahasa Indonesia. Jakarta : Diksi Insan Mulia.

Gunawan Wawan. (2010). Tip \& Trik Menulis Buku. Bandung : AIPI.

Keraf. (2010). Argumentasi dan Narasi. Jakarta: PT Gramedia Pustaka Utama.

Lie Anita. (2010). Cooperative Learning. Jakarta: PT Gramedia Widiasaran Indonesia.

Masnur. (2009). Melaksanakan PTK Itu Mudah (Classroom Action Research) Pedoman Praktis Bagi Guru Professional. Jakarta: PT Bumi Aksara.

Nurgiyantoro, Burhan. (2001). Penilaian dalam Pengajaran Bahasa dan Sastra Indonesia. Yogyakarta: BPFE.
Riyanto. (2010). Paradigma Baru Pembelajaran. Jakarta: Kencana Prenada Media Group.

Rose, Nicholl. (2002). The Accerelated Learning For The 21ST Century. Diterjemahkan oleh Dedy Ahimsa. Bandung:Nuansa.

Semi. (2007). Dasar-dasar Keterampilan Menulis. Bandung: Angkasa.

Slavin. (2010). Cooperatif Learning. Penerjemah oleh Narulita Yusron.Bandung: Nusa Media.

Solihatin, Raharjo. (2009). Cooperative Learning Analisis Model Pembelajaran IPS. Jakarta: PT Bumi Aksara.

Suhendar, Supinah. (1997). MKDU (Mata Kuliah DasarUmum). Bandung Pionir Jaya

Syamsuddin, Vismaia. (2006). Metode Penelitian Pendidikan Bahasa. Bandung: Remaja Rosdakarya.

Tarigan. (1994). Menulis Sebagai Suatu Teknik Keterampilan Berbahasa. Bandung: Angkasa.

Universitas Pendidikan Indonesia. (2009). Bahasa dan Sasatra dalam Presfektif Pendidikan. Bandung: UPI.

Uniniversitas Pendidikan Indonesia. (2009). Bahasa dan Sastra Indonesia di tengah Arus Global. Bandung: UPI.

Universitas Penidikan Indonesia. (2003). Pedoman Penulisan Karya Ilmiah. Bandung: UPI. 